\title{
"Narrow" Thinking About Difficult Weaning: Don't Forget the Endotracheal Tube
}

Liberating a patient from mechanical ventilation (often referred to as weaning) remains a major challenge in critical care. Studies performed in the 1990s suggested the process was simpler than previously supposed. Those studies indicated that $65-85 \%$ of patients recovering from acute respiratory failure of various causes passed their initial unsupported (or minimally supported) spontaneous breathing trial (SBT) and could be extubated, most successfully. ${ }^{1-3}$ These observations were enlightening in showing that only a minority of patients required the traditional approach to weaning: a slow, methodical, often time-consuming, stepwise reduction in ventilatory support. Yet these studies were also quite deceptive in suggesting that the process was simple and straightforward.

More recent reports, using definitions proposed by a consensus conference, indicate that liberation is frequently not so simple (Table). ${ }^{4}$ As an example, Funk et al, studying 257 patients, found that only $59 \%$ experienced simple weaning, while $26 \%$ were difficult and $14 \%$ prolonged. ${ }^{5} \mathrm{~A}$ much larger, multicenter observational study of 2,714 patients found that only $55 \%$ of weaning was simple. ${ }^{6}$ Together these studies indicate that more than $40 \%$ of all mechanically ventilated patients who improve to the point where weaning is initiated, prove to be difficult to wean.

An appreciation of the difficulty and complexity of liberation highlights 2 important areas to be addressed: How can we identify and then reverse the pathophysiologic processes that make it more difficult to liberate a patient from mechanical ventilation? How can we best identify the earliest time that a patient is ready for spontaneous breathing?

There is considerable evidence to suggest that the endotracheal tube (ETT) can impede liberation from mechanical ventilation. By increasing the work of breathing (imposed work of breathing), the ETT may unfavorably tip the balance between the load on the respiratory system and the capacity of the system to confront that load (loadcapacity imbalance). Bench studies demonstrate that narrowing the internal diameter of the ETT increases the work of breathing. ${ }^{7,8}$ The observation is not unexpected, as tube resistance varies inversely with tube radius raised to the fourth power. Thus, a small reduction in ETT internal diameter could result in a large increase in resistance, thus increasing the work needed to overcome that resistance. That said, the clinical relevance of this has been ques-
Table. Definitions of Simple, Difficult, and Prolonged Weaning

\begin{tabular}{lc}
\hline \hline Weaning Type & Definition \\
\hline Simple & First spontaneous breathing trial (SBT) \\
& successful, extubation successful \\
Difficult & Fails first SBT and requires up to 3 SBTs before \\
& successful (and 7 days or less from first SBT \\
& to successful SBT) \\
Prolonged & Fails at least 3 SBTs or requires $>7$ days from \\
& first SBT to successful SBT \\
\hline
\end{tabular}

tioned because the relatively low inspiratory flow rates generated during spontaneous breathing appear to result in only modest increases in work of breathing when breathing through a narrower ETT. ${ }^{9}$ This suggests that the effect of a narrow tube will be clinically relevant only at internal diameters narrower than typically used.

In addition, some authors have found that work of breathing associated with inspiration through an ETT is no greater than that encountered after the tube has been removed. ${ }^{10}$ Unfortunately, such studies fail to shed light on the issue, as they examine only patients who passed the SBT (despite the narrower tube) and went on to extubation. Patients failing the SBT (eg, those who might encounter high imposed work of breathing from the tube) are not included. Moreover, recent work demonstrates that ETT diameters may narrow more severely than previously suspected, and do so more rapidly than anticipated. Wilson and colleagues, studying ETTs after extubation, found that organized secretions narrowed the tube lumen and might affect patient tolerance for weaning. ${ }^{11}$ Half the time the tube behaved like one with a $1 \mathrm{~mm}$ narrower internal diameter; up to $15 \%$ of the time that narrowing was the equivalent of a tube $3 \mathrm{~mm}$ narrower. In this latter instance, tube diameter may decrease to the point where the degree of narrowing is physiologically important.

Several studies indicate that the ETT can contribute to intolerance for spontaneous breathing (weaning intolerance or iatrogenic weaning failure). Studies of patients in a trauma ICU found an association between elevated measured imposed work of breathing and weaning intolerance (manifested as tachypnea). ${ }^{12,13}$ In fact, these investigators found that when the physiologic work of breathing (equal to total minus imposed work of breathing) was in the 
normal range, patients could be extubated successfully. Ezingeard et al placed 31 patients failing a $30 \mathrm{~min}$ T-tube trial on pressure support $\left(7 \mathrm{~cm} \mathrm{H}_{2} \mathrm{O}\right)$, finding that 21 tolerated the additional $30 \mathrm{~min}$ trial and 17 were successfully extubated. ${ }^{14}$ It is tempting to speculate that some patients in this group were failing because of excessive imposed work of breathing related to the ETT, and this additional load was offset by the application of low level pressure support. If that is the case, what explains the failure of automatic tube compensation, an approach designed to deliver a varying level of pressure support to overcome imposed work of breathing (without overcompensating), to outperform SBTs conducted on CPAP, T-tube, or a set level of pressure support? ${ }^{15-17}$ With automatic tube compensation the level of pressure support delivered is a function of the pre-intubation characteristics of the ETT. As noted earlier, those characteristics may quickly and substantially change after the ETT is in place. Failure to detect this change in ETT internal diameter may explain why automatic tube compensation has not been of benefit, compared to other SBT approaches. Finally, in acute on chronic respiratory failure from COPD, noninvasive ventilation may allow for successful extubation of patients not tolerating SBTs. ${ }^{18,19}$ It is possible that some of these patients were failing because of the excess work of breathing imposed by the ETT.

See the Original Study on Page 2012

The concept that the ETT can substantially increase work of breathing is strengthened by the observations of Valentini and co-workers in this edition of ReSPIRATORY CARE. ${ }^{20}$ The authors studied the effect of tracheotomy tube diameter on diaphragmatic effort in 10 difficult to wean subjects. The authors compared breathing through tracheotomy tubes with different internal diameters by randomly studying their subjects with and without the inner cannula. When compared to the $8 \mathrm{~mm}$ internal diameter tube, breathing through the narrower $(6.5 \mathrm{~mm}$ internal diameter $)$ inner cannula resulted in significantly increased diaphragmatic effort, as assessed by measurement of the pressure-time product, which increased by $28 \%$, most likely a result of the $41 \%$ increase in measured resistance. The authors further noted an increased tension-time index of the diaphragm, a direct measure of the balance between load and capacity, during breathing with the inner cannula in place. The authors also performed an in vitro study that showed changes in resistance were similar in ETTs; resistance was increased with a $6.5 \mathrm{~mm}$, compared to an $8 \mathrm{~mm}$, internal diameter ETT.

Of the many physiologic parameters used to assess readiness for an SBT, the rapid shallow breathing index, or frequency to tidal volume ratio $\left(\mathrm{f} / \mathrm{V}_{\mathrm{T}}\right)$, is the most com- prehensively investigated. Load-capacity imbalance is a common cause of failed SBTs and is associated with a pattern of rapid shallow breathing. The one randomized controlled trial of $f / V_{T}$ failed to show improved outcome; use of the $\mathrm{f} / \mathrm{V}_{\mathrm{T}}$ to guide weaning decisions did not shorten the duration of mechanical ventilation. ${ }^{21}$ Other conditions are associated with the pattern of rapid shallow breathing, including supine position, anxiety, fever, and female sex. These factors may explain why some patients with rapid shallow breathing tolerate an SBT and are successfully extubated. We have previously shown that mechanically ventilated medical ICU patients with narrow ETTs $(\leq 7 \mathrm{~mm}$ in diameter) have a higher $\mathrm{f} / \mathrm{V}_{\mathrm{T}}$ than those with larger tubes $(>7 \mathrm{~mm}) .^{22}$ Mehta and colleagues made similar observations, finding a higher $f / V_{T}$ in patients with $7-7.5 \mathrm{~mm}$ ETTs, compared to those with $8 \mathrm{~mm}$ tubes. ${ }^{23} \mathrm{In}$ studying the effects of breathing through a narrowed tracheotomy tube, Valentini et al also examined the effect on $\mathrm{f} / \mathrm{V}_{\mathrm{T}}$. In agreement with our work and that of Mehta et al, Valentini found a higher $f / V_{T}$ when breathing occurred through the $6.5 \mathrm{~mm}$ inner cannula, compared to the $8 \mathrm{~mm}$ internal diameter without the cannula ( $\mathrm{f} / \mathrm{V}_{\mathrm{T}} 93$ vs 77 ). Four of 10 patients had an f/VT above the threshold of 100 associated with weaning failure, but in 3 of these the elevated $f / V_{T}$ occurred only when breathing through the inner cannula. If the imposed work of breathing is contributing to intolerance for spontaneous breathing, the elevated $f / V_{T}$ will be accurately associated with weaning failure (eg, a true negative test predicts failure and the patient fails). Conversely, should such a patient be given a trial of extubation and tolerate it, the test would be classified as false negative.

The study by Valentini and co-workers reminds us that we must consider the physiologic effects of the artificial airway as we attempt to liberate the patient from mechanical ventilation. Measurements showing increased airways resistance may, in the absence of factors suggesting the problem resides in the native airways, indicate that the ETT or tracheotomy tube has become excessively narrowed. For clinicians using the $\mathrm{f} / \mathrm{V}_{\mathrm{T}}$ in their weaning decision-making algorithm, rapid shallow breathing in a patient with difficult weaning, without another explanation, should raise the possibility that the ETT is the culprit.

Scott K Epstein MD Office of Educational Affairs Division of Pulmonary, Critical Care, and Sleep Medicine Tufts Medical Center Tufts University School of Medicine Boston, Massachusetts 


\section{“Narrow" Thinking About Difficult Weaning: Don’t Forget the Endotracheal Tube}

\section{REFERENCES}

1. Brochard L, Rauss A, Benito S, Conti G, Mancebo J, Rekik N, et al. Comparison of three methods of gradual withdrawal from ventilatory support during weaning from mechanical ventilation. Am J Respir Crit Care Med 1994;150(4):896-903.

2. Esteban A, Frutos F, Tobin MJ, Alía I, Solsona JF, Valverdú I, et al. A comparison of four methods of weaning patients from mechanical ventilation. Spanish Lung Failure Collaborative Group. N Engl J Med 1995;332(6):345-350.

3. Vallverdu I, Calaf N, Subirana M, Net A, Benito S, Mancebo J. Clinical characteristics, respiratory functional parameters, and outcome of a two-hour T-piece trial in patients weaning from mechanical ventilation. Am J Respir Crit Care Med 1998;158(6):1855-1862.

4. Boles JM, Bion J, Connors A, Herridge M, Marsh B, Melot C, et al. Weaning from mechanical ventilation. Eur Respir J 2007;29(5): 10331056.

5. Funk GC, Anders S, Breyer MK, Burghuber OC, Edelmann G, Heindl $\mathrm{W}$, et al. Incidence and outcome of weaning from mechanical ventilation according to new categories. Eur Respir J 2010;35(1):88-94.

6. Penuelas O, Frutos-Vivar F, Fernandez C, Anzueto A, Epstein SK, Apezteguía C, et al. Characteristics and outcomes of ventilated patients according to time to liberation from mechanical ventilation. Am J Respir Crit Care Med 2011;184(4):430-437.

7. Wright PE, Marini JJ, Bernard GR. In vitro versus in vivo comparison of endotracheal tube airflow resistance. Am Rev Respir Dis 1989;140(1):10-16.

8. Bolder PM, Healy TE, Bolder AR, Beatty PC, Kay B. The extra work of breathing through adult endotracheal tubes. Anesth Analg 1986;65(8):853-859.

9. Weissman C, Askanazi J, Rosenbaum SH, Damask MC, Hyman AI, Kinney JM. Response to tubular airway resistance in normal subjects and postoperative patients. Anesthesiology 1986;64(3):353-358.

10. Nathan SD, Ishaaya AM, Koerner SK, Belman MJ. Prediction of minimal pressure support during weaning from mechanical ventilation. Chest 1993;103(4):1215-1219.

The author has disclosed no conflicts of interest.

Correspondence: Scott K Epstein MD, Office of Educational Affairs, Tufts University School of Medicine, 136 Harrison Avenue, Sackler 317, Boston MA 02111. E-mail: scott.epstein@tufts.edu.

DOI: $10.4187 /$ respcare. 02212
11. Wilson AM, Gray DM, Thomas JG. Increases in endotracheal tube resistance are unpredictable relative to duration of intubation. Chest 2009;136(4):1006-1013.

12. DeHaven CB, Kirton OC, Morgan JP, Hart AM, Shatz DV, Civetta JM. Breathing measurement reduces false-negative classification of tachypneic preextubation trial failures. Crit Care Med 1996;24(6): 976-980.

13. Kirton OC, DeHaven CB, Morgan JP, Windsor J, Civetta JM. Elevated imposed work of breathing masquerading as ventilator weaning intolerance. Chest 1995;108(4):1021-1025.

14. Ezingeard E, Diconne E, Guyomarc'h S, Venet C, Page D, Gery P, et al. Weaning from mechanical ventilation with pressure support in patients failing a T-tube trial of spontaneous breathing. Intensive Care Med 2006;32(1):165-169.

15. Cohen J, Shapiro M, Grozovski E, Fox B, Lev S, Singer P. Prediction of extubation outcome: a randomised, controlled trial with automatic tube compensation vs pressure support ventilation. Crit Care 2009;13(1):R21.

16. Cohen JD, Shapiro M, Grozovski E, Lev S, Fisher H, Singer P. Extubation outcome following a spontaneous breathing trial with automatic tube compensation versus continuous positive airway pressure. Crit Care Med 2006;34(3):682-686.

17. Haberthur C, Mols G, Elsasser S, Bingisser R, Stocker R, Guttmann J. Extubation after breathing trials with automatic tube compensation, T-tube, or pressure support ventilation Acta Anaesthesiol Scand 2002;46(8):973-979.

18. Burns KE, Adhikari NK, Keenan SP, Meade M. Use of non-invasive ventilation to wean critically ill adults off invasive ventilation: metaanalysis and systematic review. BMJ 2009;338:b1574.

19. Girault C, Bubenheim M, Abroug F, Diehl JL, Elatrous S, Beuret P, et al. Noninvasive ventilation and weaning in patients with chronic hypercapnic respiratory failure: a randomized multicenter trial. Am J Respir Crit Care Med 2011;184(6):672-679.

20. Valentini I, Tonveronachi E, Gregoretti C, Mega C, Fasano L, Pisani L, Nava S. Different tracheotomy tube diameters influence diaphragmatic effort and indices of weanability in difficult to wean patients. Respir Care. 2012;57(12):2012-2018.

21. Tanios MA, Nevins ML, Hendra KP, Cardinal P, Allan JE, Naumova $\mathrm{EN}$, et al. A randomized, controlled trial of the role of weaning predictors in clinical decision-making. Crit Care Med 2006;34(10): 2530-2535.

22. Epstein SK, Ciubotaru RL. Influence of gender and endotracheal tube size on preextubation breathing pattern. Am J Respir Crit Care Med 1996;154(6 Pt 1):1647-1652.

23. Mehta S, Heffer MJ, Maham N, Nelson DL, Klinger JR, Levy MM. Impact of endotracheal tube size on preextubation respiratory variables. J Crit Care 2010;25(3):483-488. 